\title{
LA MEMORIA DEL ÚLTIMO EXILIO ESPAÑOL EN LA ESCRITURA DE TRES MUJERES: VICTORIA KENT, DOLORES IBÁRRURI Y CARMEN PARGA *
}

\author{
Bettina Pacheco **
}

\begin{abstract}
Resumen: Este artículo realiza un somero análisis de tres obras testimoniales del exilio escritas por mujeres: Victoria Kent, destacada abogada socialista comprometida con el gobierno de la República española, Dolores Ibárruri, la mítica Pasionaria, y Carmen Parga, republicana exiliada en Rusia $y$ México. Las tres dan su visión, a su manera y a través de la escritura, sobre el drama vivido ofreciendo su concepción particular del exilio. Antes de entrar en las obras aludidas, se examina brevemente las dos concepciones sobre la dramática experiencia del exiliado que Claudio Guillén ba reconocido en la escritura de dos clásicos: Ovidio y Plutarco.
\end{abstract}

\section{Los principios ovidiano y plutarqueo del exillio}

Los dramáticos acontecimientos vividos por los vencidos luego de la guerra civil española del 36, los obligaron a padecer un largo y, para muchos, definitivo exilio. No hay duda de que los exiliados que fueron a las Américas resultaron los más

\footnotetext{
- Recebido para publicação em janeiro de 2002.

* Universidad de Los Andes, Venezuela.
} 
favorecidos puesto que se libraron de vivir otra guerra, del horror nazi, de los campos de concentración y de los malos tratos padecidos por los que fueron a parar a Francia. Junto a esto la hermandad que de entrada ofrecía el idioma así como la buena acogida, no sin contradicciones y los inevitables rechazos, recibida por parte de países sudamericanos como México, produjo una buena integración sobre todo de aquellos intelectuales que con su trabajo hicieron una importante aportación al desarrollo de la vida cultural de estos países.

La manifestación literaria por excelencia que recogió el drama humano, social y cultural de todo un pueblo fue la de las memorias testimoniales. Acusada por algunos críticos dè ser una literatura demasiado realista y poco imaginativa debido a sus escasos valores estéticos, la narrativa sobre el exilio español del 39 parece confrontar "la imposibilidad de recrear el drama de una experiencia real y terrible, una experiencia que podríamos llamar épica" (NAHARRO-CALDERÓN, 1991: 44). Debo aclarar que entiendo por memorias testimoniales aquellas en las que el autor/a habla poco de la intimidad de su yo ya que su interés está centrado en contar los avatares sufridos por un colectivo humano, durante una determinada crisis vital casi siempre sociohistórica.

Según Claudio Guillén la mil veces reiniciada experiencia del exilio humano adopta variadas formas. Aunque el fenómeno ha acompañado a la humanidad a lo largo de su historia, esta experiencia no es siempre la misma puesto que cambia con los tiempos, con el hombre y su concepción del mundo. Por ello serán varias las respuestas que se darán al fenómeno de la pérdida de la patria en la que se ha nacido, fenómeno que es siempre el mismo y, sin embargo, siempre distinto. Y entre esas variadas respuestas destaca en importancia la respuesta literaria. No obstante, como en todo lo humano, hay en esta experiencia 
del exilio, tanto como vivencia como en su expresión literaria, una relación simultánea e interdependiente entre el cambio y la permanencia.

Esta doble circunstancia la aprecia Guillén en dos actitudes distintas con las que se puede vivir el exilio. Una de ellas surge como metáfora, la sugerida por Plutarco: la metáfora solar que permite apreciar la experiencia universal de contemplación de los mismos astros - el sol, las estrellas que refulgen en el firmamento -, compartida por los hombres y mujeres desterrados con otros hombres y mujeres de otras tierras, obedeciendo a "un proceso común y un impulso solidario de alcance siempre más amplio: filosófico, o religioso, o político, o poético" (GUILLÉN, 1995: 14).

Una segunda valoración o respuesta, asociada u opuesta a la primera, es la concepción del exilio como una pérdida, como una fractura irreparable del yo separado de los signos que daban sentido a la vida cotidiana y a la unidad psíquica. Tal fue la vivencia de Ovidio y de todos aquellos poetas o intelectuales exiliados voluntariamente dentro de su propio país. De modo que un mismo acontecimiento puede producir la universalización de una experiencia y/o una crisis social del yo.

La primera concepción fue expuesta por Plutarco en una epístola titulada De exilio, con la que se proponía refutar posiciones como la de Eurípides en sus Fenicias, según las cuales el exilio sólo trae males consigo. La propuesta de Plutarco es la de considerar al hombre como parte del amplio reino de la naturaleza y que por lo tanto tiene muchas cosas en común con el resto de la humanidad, regido como está por leyes cósmicas que nos amparan a todos.

Era ésta, según Guillén, la misma posición de los estoicos quienes consideraban a los seres humanos como ciudadanos del mundo, además de que éstos asumían que el exilio no es una 
desgracia sino una prueba, una oportunidad para que el hombre aprenda a sobreponerse sobre las circunstancias externas en atención a su mundo interior, en sincronía con el orden del universo. Es por ello que Séneca consideraba que "el espíritu nunca puede padecer exilio".

Los cínicos, por su parte, que coinciden con los estoicos en ésta visión positiva del exilio, desterrados voluntariamente de la sociedad nunca se exiliaron del lenguaje por lo que se entiende que para Diógenes Laercio la libertad de expresión sea el don más preciado. La otra respuesta poética de la tradición occidental a la experiencia del exilio fue la de Ovidio, quien tampoco renunció al lenguaje. Opuesto a la posturáa cínicoestoica, la réplica de Ovidio será la de la lamentación y la nostalgia del exiliado.

Por otra parte, Guillén diferencia entre una "literatura del exilio", en la cual el poeta expone sus experiencias situándose en él, y la "literatura de contraexilio", en la que el poeta escribe desde el exilio, distanciándose de él, acercándose a las nuevas condiciones sociales y políticas, explorándolas lingüística è ideológicamente, para así incorporarlas. Ovidio hace una literatura del primer tipo, cultivando dos géneros arquetípicos: el elegíaco, que señala una ausencia, y el epistolar que intenta suprimirla y remediarla. La importancia de este autor, destacada por Guillén, es la de convertir el exilio en tema literario, a diferencia de Séneca o Plutarco para quienes sólo es objeto de reflexión moral.

Estas dos valoraciones opuestas, legadas por la Antigüedad y que Guillén denomina principios ovidiano y plutarqueo, tienen su evolución a lo largo de los diferentes estadios de la historia. De modo que durante la Edad Media la tradición ovidiana será motivo de reflexión, con la que se llega a considerar al exilio como un camino hacia la búsqueda de la 
perfección "del alma errante". Dicho aprendizaje implicará el ineludible dolor así como el esfuerzo por superar el desarraigo y las pérdidas que todo exilio trae consigo. En Dante, por ejemplo, es notable el diálogo, la tensión, entre la concepción ovidiana del exilio como sufrimiento y la otra perspectiva, la de la posibilidad de enriquecimiento y ampliación de la experiencia humana.

Con el Renacimiento se asumirá el tema del exilio en plenitud como asunto literario. Esto porque es en este período, según Guillén, cuando se funden o confunden las figuras de Ovidio y Ulises, "supremo ejemplo de la voluntad de retorno", lo que es igual a la fusión o confusión entre la literatura y la vida, de un personaje mítico con un poeta que ha convertido el tema del exilio en asunto literario. La experiencia del exilio en los siglos XVI y XVII se asocia al afianzamiento del nacionalismo en los principales países europeos debido a la unificación religiosa y política y al poder monárquico.

Andando el tiempo, ampliándose la experiencia del exilio en las proximidades de la modernidad, desde la revolución francesa hasta nuestro siglo - traducida en expulsiones, destierros colectivos, migraciones masivas - junto al fenómeno del nacionalismo, de la concepción de la cultura como todo aquello que es específico o distintivo de un pueblo, podría decirse que la concepción predominante será la de Ovidio, la de la nostalgia de lo propio, de lo local. Aquí Guillén se pregunta de si sería posible llegar a concebir al exilio como metáfora de la soledad el hombre, del artista, dentro de la sociedad fracturada.

Adentrados ya en la modernidad, asumida la nacionalización de la cultura afianzada en el siglo XIX, cuando se toma lo singular como rasgo de unidad, surge también, frente a este auge nacionalista, la tendencia opuesta a la añoranza, como 
es la del escritor voluntariamente desarraigado, alejado de su lugar de origen como elección de su destino individual. De modo que el exilio en la modernidad estará tocado por los signos que hacen de esta experiencia "maduración y regreso, novedad y repetición". La temporalidad moderna procurará que el regreso del emigrado sea difícil, irreal o imposible, ya que en muchos casos la experiencia del exiliado lo ha inscrito en la internacionalidad y la universalidad.

De modo que Guillén considera que los límites entre la realidad del exilio y su metáfora, es decir, entre el exilio real, palpable, y el exilio interior y su consecuente traducción en escritura, son cada vez más borrosos y que las dos pòsiciones perduran como tema en la literatura contemporánea. Sólo cabe preguntarse ahora ¿cómo vivieron su experiencia de exiliadas Victoria Kent, Dolores Ibárruri y Carmen Parga?

\section{Las memorias literarias de Victoria Kent}

Las memorias de Victoria Kent, quien fuera directora de prisiones durante la República y la primera mujer penalista en España, se apartan bastante de un proyecto memorialístico al uso ya que responden a la porosidad de los géneros que caracteriza a la literatura moderna. Es observable desde el inicio la intención novelesca de las dos primeras partes del texto. De entrada nos sorprende que un narrador en tercera persona nos comente el deambular por la ciudad de un personaje solitario: Plácido. Aún a sabiendas, por el prólogo y la fotografía de la autora que preceden al texto en la edición facsimilar utilizada para este estudio, que Plácido y la autora son la misma persona, la impresión de alejamiento que produce al lector no puede evitarse. Tal efecto de buscado distanciamiento podría leerse como metáfora del encierro y ocultamiento del yo ante los 
propios lectores, fiel reflejo de la condición de refugiado y perseguido del personaje.

De modo que un tanto desconcertados como lectores penetramos en lo que podríamos llamar una autobiografía mental novelada, dado que en estas dos primeras partes en las que se nos presenta al personaje nos sumergimos en un monólogo interiorizado de un perseguido que se esconde del fascismo, de los delatores. Así expone ante nosotros, un discurso que media entre lo filosófico y lo ensayístico donde se discurre sobre la vida, la muerte, la patria, el exilio y la libertad, tema al que alude obsesivamente.

En medio del constante discurrir mental, se insertan diálogos y ciertas acciones del personaje enclaustrado-pensador que le otorgan el tinte novelesco al relato. También se suceden saltos de la tercera a la primera persona cuando se le otorga voz al personaje. De modo que estas dos primeras partes se desarrollan en medio de una mezcla de géneros y narradores no del todo lograda, desde el momento en que el resultado es más de confusión que de efecto estético.

Sin embargo, quiero destacar dos aciertos. Uno lo constituye el tono del relato, totalmente sobrio y desdramatizado a pesar de la mirada desencantada sobre el mundo y sobre el ser humano que ofrece al lector. El otro es la inclusión del elemento fantástico al poner a hablar al personaje, en medio de su aislamiento, con su reloj y con una pelota con la que juega. Son éstas unas incursiones muy breves por lo demás, pero que acentúan la intención estética del proyecto memorialístico, lo que no deja de sorprender dada la trayectoria pública de la autora ajena a las lides literarias.

Mis expectativas de lectora deseaban quizá un texto que hiciera más alusión al desempeño político de la autora y a la guerra civil española, no obstante, su obsesión es el pen- 
samiento, la reflexión más que la anécdota o la justificación de sus actuaciones. No hay intención historicista, es evidente que estamos muy lejos de las memorias del siglo XTX, lo que no quiere decir que dentro de su proyecto ideológico no esté el de manifestar la firmeza de sus convicciones, como lo demuestra una frase tan militante como ésta: “... los hombres siembran ideas antes de morir por ellas, y las ideas escapan a la muerte"(KENT, 1997: 16).

A esta altura es posible plantearse otra interrogante: ¿cuál es, en definitiva, el proyecto ideológico de estas memorias de Victoria Kent? En primer lugar, me parece que son un documento contra el olvido como es común al memorialismo del exilio:

Yo no quiero olvidar todo lo que hoy sé. Que otros hagan la Historia y cuenten lo que quieran; lo que yo quiero es no olvidar, y como nuestra capacidad de olvido lo digiere todo, lo tritura todo, lo que hoy sé quiero sujetarlo en este papel (p. 159).

Es por ello que en las dos últimas partes del libro, el personaje Plácido desaparece y ya es la voz de la autora la que, en primera persona, recupera el relato para contar pequeños sucesos desencadenados por el terror nazi del que ella ha sido testigo. Campos de concentración, personajes heroicos, clima de persecución y muerte, se recogen en breves fragmentos fechados al modo de los diarios íntimos. Esta preocupación por fechar, tanto cada una de las partes que constituyen el libro como los sucesivos pasajes de las dos últimas, revelan el afán de verosimilitud de la autora, de dejar un testimonio que se lea como un documento auténtico.

Otro propósito, no tan evidente puesto que no se expresa 
directamente, pero que se deduce con cierta facilidad, es la denuncia de la indiferencia de los franceses con respecto, a la guerra de España. Esto se hace notable en algunas críticas que hace la autora al racionalismo francés, al excesivo apego a la lógica que no los deja tomar decisiones audaces, lo que la lleva a preguntarse qué hubiera pasado si todo el pueblo parisino se hubiera levantado contra los nazis, si éstos se hubieran atrevido a ametrallarlos a todos. Aquí, sin que lo diga abiertamente, pareciera hacer una comparación tácita con el pueblo español y sus levantamientos contra los invasores.

La concepción ovidiana del exilio patente en esta obra que es un texto escrito desde y sobre del exilio, se revela en este significativo pasaje:

En esta realidad de acero de la vida actual puede parecer que el exilio es lo de menos para el hombre; nada de eso. El exilio sigue siendo una fuente inagotable de sufrimientos. Mucho se ha escrito sobre el dolor del destierro; sea como sea, hemos de aceptar que el hombre lejos de su patria es un árbol sin raíces y sin hojas; lucha para mantenerse firme sobre la tierra y nadie puede descansar bajo su sombra.

Ovidio dijo: "En saliendo de su patria, equién puede decir que sigue siendo el mismo?". Y ésta es la tragedia del hombre en el destierro: su brazo no dirige, su mirada no abarca sino horizontes bien limitados, su voz no llega a ninguna parte. (p. 74)

Con lo dicho, Victoria no hace más que retratar su propia condición, ya que después de haber jugado roles tan destacados en medio de la realidad social y política de su país, se encontraba reducida a transitar a hurtadillas por un país que no 
era el suyo, con identidad y papeles falsos y con un pasaporte que llevaba impresa en letras moradas la infamante palabra refugié.

No se olvida la autora de hacer un reconocimiento a las mujeres, reaccionando en contra de la opinión que ella le atribuye a los hombres desterrados, según la cual el hombre sufré un dolor más profundo en el destierro que la mujer, puesto que para ésta la patria es el hogar que siempre va con ella. Piensa que se le debe justicia a las mujeres tanto en este terreno como en otras muchas cosas y manifiesta su fe en que poco a poco se le hará, de ahí su rotunda afirmación referida a las reivindicaciones que se le debe a las mujeres: "confío en el futuro".

Estas memorias contra el olvido, cuyo tono lírico marcan su originalidad con respecto a otros textos memorialísticos escritos por mujeres, como bien opina de Neus Samblancat (SAMBLACAT, 1997: 9), demuestran, a mi entender, un intento de sobrevivencia ya que el ejercicio memorístico prueba que no todo está perdido, que queda el recuerdo, aunque esté teñido de nostalgia y de fracaso. Las autoras de las memorias del exilio parecieran querer decirnos que contra el naufragio del olvido, la escritura es la tabla de salvación.

\section{Dolores Ibárruri: la hagiografía del comunismo}

Como es usual en la escritura memorialista del exilio, Dolores Ibárruri no tematiza su yo más íntimo como protagonista de su relato. Su interés es el de ofrecer las memorias de su actividad como militante comunista fuera de España, privilegiando su acción pública, con pocas alusiones al ámbito de lo privado. No hay referencias al amor de pareja, a la vida íntima en su cotidianidad, aunque no oculta emociones 
como la del dolor que le produce la muerte de su hijo en el frente ruso durante la segunda guerra mundial. La hija es apenas mencionada, así como su amistad y colaboración con Irene Falcón, con lo que no le concede un espacio al tema de la amistad femenina ni al de las relaciones madre-hija. De modo que la subjetividad de Pasionaria se reafirma en el espacio de la vida pública, se muestra segura de sus logros y de la importancia de su estar y hacer en el mundo, aunque las alabanzas y los reconocimientos los ponga en boca de terceros, como es usual en el memorialismo femenino.

Tampoco nos encontramos con el consabido metatexto que introduce, explica o justifica el proyecto autobiográfico. En su lugar, en una breve nota titulada "Al lector", Irene Falcón, su fiel secretaria y compañera de exilio por tantos años, confiesa que colaboró en este libro a petición de Pasionaria, pero sin especificar de qué manera. Sin embargo, sí se detendrá Dolores para dejar claro la voluntad testamentaria de su primer libro de memorias, El único camino, cuya razón de ser queda justificada por la necesidad de que sus nietos y todos los jóvenes conozcan el nacimiento del movimiento obrero en España, así como las luchas y sacrificios de los trabajadores en los años de la República y la guerra civil, para que así pudieran sintonizar con las luchas y padecimientos de sus mayores.

En esta versión del yo relacional femenino, una especie de composición a cuatro manos, Falcón desvela, en el mencionado texto introductorio, la intención del proyecto memorialístico de Pasionaria que no es otra que la de recoger con "sencillez y amenidad" vivencias y anécdotas sucedidas en cuarenta años de exilio. Como también es usual en gran parte del memorialismo de mujeres, la propuesta inicial confesada por las escritoras contempla una pasaje que expresa la bumilitas rethorica, ya que se cuidan de dejar muy en claro la simple intención de 
contar unas vivencias y no de construir un documento monumental, aclaratoria presente también en las memorias de Carmen Parga como comentaré más adelante.

De modo que Pasionaria se nos va perfilando, indirectamente, a través de sus anécdotas, de sus discursos intercalados en el cuerpo de la narración, de los retratos de personajes destacados del comunismo español e internacional, como la madre, la oradora líder del partido comunista y, sobre todo, como la revolucionaria hija y esposa de mineros que se convirtió en mito. A pesar del tono sencillo y directo que rezuma sinceridad, no se deja de percibir que ella misma participa en la construcción de su propia leyenda.

Su actitud conciliadora, prudente, que pareciera no haberse dado cuenta de las atrocidades del estalinismo, de los padecimientos del pueblo ruso, tal como los denuncia Carmen Parga, su constante abogar por la unidad y apertura contra el sectarismo, hacen que en este texto no aparezca la más mínima reflexión o censura a los errores del comunismo, de las ideas en las que creyó y a las que dedicó su vida entera.

El texto comienza haciendo alusión a El último camino, del que es continuidad, de modo que el carácter autorreferencial del mismo está marcado doblemente puesto que parte de una obra propia escrita con anterioridad, no para hacer análisis histórico ni teórico sino para contar simplemente, para manifestarse contra el olvido, y, con ello, sustentar el mito: la Pasionaria "la verdadera representante de España"(IBÁRRURI, 1984: 173).

La autorreferencialidad se hará más marcada gracias a la intertextualidad que caracteriza a estas memorias ya que constantemente la autora incluirá fragmentos de los discursos pronunciados en los diversos eventos, congresos, mitines y entierros, en los que participó, como una manera de eternizar en papel y tinta, esa voz calificada como única y extraordinaria 
según la mayoría de los testimonios que de ella se han hecho.

Los famosos discursos de Pasionaria que ella se esmera en registrar cuidadosamente - suponemos que la colaboración de Irene Falcón se centró, fundamentalmente, en cumplir la labor de recopilación de éstos más que en la escritura misma -, se convierten además en una valoración del documento como legitimación de la veracidad de lo contado. Tales discursos se entretejen en medio de la heterogeneidad de la estructura de este texto en el que se combinan, a modo de breves apartes con título, respetando un orden que intenta ser cronológico, con las historias narradas.

Estos breves apartes registrarán anécdotas, sucesos de trascendencia histórica, las actuaciones de la Internacional Comunista, junto a la semblanza de personajes destacados, militantes comunistas de los que da cuenta resaltando su encomiable humanidad, su destacada acción social y política, sus sacrificios, así como la prematura y dolorosa muerte de algunos de ellos. Este tipo de retratismo contra el olvido es común al memorialismo del exilio, así como la costumbre de incluir listas de nombres como homenaje a la memoria de los caídos, en un afán de levantar una nómina a modo de registro de aquellos a los que no se debería olvidar.

También es necesario mencionar la presencia de otra constante como es la referencia a las memorias escritas por otros autores, posibles hipotextos del propio ejercicio memorístico. Así menciona las memorias de Ignacio Hidalgo de Cisneros, con las que tiene una pequeña discrepancia en un dato por él incluido; igualmente hace alusión a las memorias de Anthony Eden, a los Recuerdos de Francisco Largo Caballero y a Hijo del pueblo de Maurice Thorez.

Merece destacarse muy especialmente el espacio dedicado a las mujeres, puesto que en memorias como las de Constancia 
de la Mora o Victoria Kent pareciera que la guerra fuera sólo cosa de hombres, como si el heroísmo de ellas no mereciera especial mención. Pasionaria, por el contrario, se detiene un tanto a considerar el rol desempeñado por las mujeres reconociendo el valor y la trayectoria de varias de ellas, con lo que hace un tributo a su relevante papel histórico. Como bien ha señalado Shirley Mangini (MAŃGINI, 1997: 197), las memorialistas del exilio demuestran preocupación por el tema de las mujeres y sus reivindicaciones.

Otra característica de este texto, que resulta además consoladora para el lector, es la excepción que constituye en cuanto al tratamiento del tema de la vejez. Pasionaria manifiesta que a los ochenta años no se siente "vieja, vieja", porque, a su eñtender, mientras se hace algo útil el alma no envejece. Resulta consolador, como dije, si contrastamos con la gran cantidad de textos autobiográficos en los que el autor se lamenta del estado de deterioro que trae consigo la vejez. Puede que esto se deba a la actitud que con respecto al exilio manifiesta la autora, actitud que podríamos entender como de un ponderado equilibrio entre el principio ovidiano y el plutarqueo, entre el eterno recuerdo y nostalgia de su patria - "me faltaba España" - y el amor a la tierra que la acogió por tantos años. Por eso dirá a propósito de su regreso a España en 1977: "Emoción, alegría... y también nostalgia. Estoy muy contenta y, al tiempo triste. Porque allí he dejado a mis nietos... y una parte de mi vida"(p. 216).

\section{Carmen Parga en el exilio ruso}

Las memorias de Carmen Parga ${ }^{1}$ comienzan con el obligado

\footnotetext{
${ }^{1}$ Carmen Parga nació en La Coruña, fue deportista y estudiante de la Universidad de Madrid, militante del partido socialista y esposa de Manuel Tagüeña, uno de los más importantes militares de la República.
} 
metatexto, "A manera de prólogo", que justifica y explica el proyecto autobiográfico. En éste nos revela que el título de las mismas, Antes que sea tarde, se explica por la edad de la autora y su función testimonial, debido a que son escritas a los ochenta años, a que son las memorias que se siente obligada a escribir antes de que la sorprenda la muerte. Afirma además no haberse apoyado en documento alguno y que éstas no tienen pretensiones de documento histórico, valor que sí tienen las de su marido Manuel Tagüeña Latorre, tituladas Testimonio de dos guerras. Estas memorias son mencionadas, citándolas brevemente en las últimas páginas de su libro, con lo cual demuestra que la afirmación de no haber tenido en cuenta documento alguno, no es del todo cierta, ya que las memorias del marido son una referencia mencionada, aunque de pasada, en otras partes del texto, lo que demuestra, una vez más, que los textos autobiográficos se remiten entre sí, unos a otros.

Calificadas por ella misma como historia de un exilio, las considera una versión femenina de esta historia, "de la gran aventura vivida por los españoles que perdimos la guerra $y$ fuimos lanzados al exilio exterior" (PARGA, 1996: 179). Esta narración será asumida, entonces, como escritura de mujer, su perspectiva será, o intentará serlo, conscientemente femenina, donde no se trata de hacer una aportación al género histórico sino de un proyecto aparentemente más sencillo: contar las anécdotas salvadas por el recuerdo, hacer la glosa de lo cotidiano, con la expresa voluntad testamentaria de legar el testimonio de los avatares del exilio a nietos y nuevas generaciones. Sin embargo la autora va más allá puesto que estas ejecuciones amenizarán el proyecto ideológico de este acto comunicativo: el desenmascaramiento del comunismo soviético, de la opresión del pueblo ruso, del desengaño producido por una postura política que Carmen Parga califica 
de irracional, de la ceguera y el consecuente fanatismo de parte de la inmigración española tanto en Rusia como en México. De ahí la función cívica de este texto, su salida a la luz pública como respuesta a la petición de amigos y familiares que se lo solicitaron una y otra vez, aclaratoria que también implica una velada justificación.

La historia contada está constituida por una etapa de la vida de la autora, aquella que transcurre entre el día en que ella perdió la guerra, hasta la muerte de Franco. La primera evocación es la de un hecho que se constituye en una toma de conciencia que funciona como suplantación del recuerdo del nacimiento, más común en la autobiografía tradicional. Por ello, el primer recuerdo lo constituirá el del "día que perdí la guerra".

Al principio, la entrada en el largo exilio es, según nos cuenta la autora, una entrada feliz, dado que tanto ella como sus acompañantes se sentían satisfechos de haberle dado cara al fascismo y de haber librado una lucha justa. Gracias a la condición de militar de alta graduación del marido, logran librarse de los campos de concentración franceses, privilegio que no parece molestarles. Abordado el barco que los llevará rumbo a la URSS, los emigrados se encuentran eufóricos en su condición de supervivientes y con una gran curiosidad por descubrir el mundo soviético. Para facilitar que el barco donde viajaban hacia el puerto de Leningrado avanzara en medio del deshielo, ya que entraba la primavera, un rompehielos les sale al encuentro.

Sin embargo una pequeña tragedia, muy grande para la autora, sucede: dos afilados bloques de hielo cercenan la aleta de una foca que, gritando como un ser humano, se aleja dejando un rastro de sangre sobre el hielo. $Y$ esta terrible imagen se convierte en la metáfora de la gran tragedia que acaba de dejar atrás y que la autora no había asumido hasta ese 
momento: la sensación de mutilación producida por la guerra con sus secuelas de muerte, de pérdida de la patria, junto a la premonición de las penurias del exilio.

Una vez desembarcados, la primera visión de Leningrado es deprimente, la primavera con su deshielo no es un bello espectáculo en Rusia, sin embargo los exiliados procuran conservar el optimismo. Este primer encuentro con las tierras de adopción, como una experiencia poco agradable a la vista, parece ser una constante del memorialismo del exilio.

La obra está dividida en pequeños apartes sin numeración ni título, que al principio se van intercalando para contar alternativamente la vida de la autora en España, centrada en su activismo político y sus estudios universitarios. En estos apartes va estructurando la crónica de la llegada a Rusia, el instalarse en una nueva vida y el progresivo desencanto ante la realidad de hambre, hacinamiento, carestía de bienes básicos, persecución, dogmatismo e injusticia que caracterizaba al régimen soviético. A medida que avanza la narración, cesan los retornos al pasado vivido en España y es la realidad del exilio la que ocupa todo el texto.

Llama la atención que casi no haya alusiones a la guerra civil, aunque sí hay recuerdos de amigos muertos. El primer retrato presentado por la autora es el de Stalin. Visto desde lejos en la Plaza Roja durante el desfile del Primero de Mayo, la visión desencantada no puede ser más significativa como evidencia del proyecto ideológico de este texto.

En medio del relato de las peripecias que traía consigo la lucha por la sobrevivencia, dentro de un medio de carestía agravada por la guerra contra los nazis, Parga nos cuenta anécdotas y destaca su papel protagónico como joven militante socialista y luego comunista, o como deportista en Madrid, así como su valentía y destacada labor como profesora o en los 
diversos trabajos que asume con gran eficacia para vivir lo mejor posible. No se nota aquí el pudor que según Carolyn Heilbrun (HEILBRUN, 1994: 97) demuestran las escritoras angloamericanas para señalar sus logros. Al contrario, varias veces se retrata como la heroína de muchos pequeños sucesos, como alguien insobornable moral e ideológicamente. Esta autoexaltación me paréce que es la motivación oculta de sus memorias, motivación que por supuesto no reconoce explícitamente.

El marido es nombrado varias veces, pero de manera muy rápida y no como protagonista de algo notable, salvo unos reconocimientos a su inteligencia y a los estudios realizados con brillantez en el exilio. Las hijas, por el contrario, se mencionan continuamente como la gran preocupación de la autora en su afán de procurarles la mejor vida posible, así como también por su destacada habilidad para aprender los idiomas, junto a su precocidad para adaptarse a la nueva situación y la inteligencia para comprender el medio en el que viven.

La visión que se nos da del exilio no es pesimista u ovidiana, antes al contrario, el exilio es visto como el lugar no sólo del enriquecimiento de conocimientos y experiencias, sino como el lugar de la toma de conciencia. La convivencia con el resignado pueblo ruso es muy valorada por considerarla enriquecedora.

Hay que destacar que, como es usual en las memorias, son pocas las referencias a la intimidad. Cuando nace una de sus hijas, por ejemplo, es poquísimo lo que expresa de ese momento, no hace referencia a sentimientos, no expresa emociones, aunque sí registra muy brevemente la experiencia corporal y dolorosa del parto, lo cual se constituye en un asomo de este tema que ha cobrado importancia en la escritura de mujeres en la actualidad. Sin embargo, que evite toda referencia a las emociones que envuelven estos eventos no deja de 
defraudar mis expectativas de lectora, esto demuestra que su proyecto memorialístico está más comprometido con la exposición de principios que con una recuperación nostálgica del pasado.

Igualmente sorprende la parquedad con la que se refiere a la muerte del padre y la objetividad con la debe reconocer las "ventajas" que trajo consigo su muerte: una boca menos y unas prendas para vender en el mercado negro. Se trata de una censura del duelo, como si se desacralizara la muerte de tanto convivir con ella, lo que podría leerse como una franca defensa ante su proximidad. Igual parquedad demuestra al hablar de la muerte de la madre y la prematura desaparición del marido, sucesos contados en pocas líneas, mientras, seguidamente, le dedica página y media al comentario de la muerte de Franco.

De modo que Carmen Parga está más interesada en realizar una radiografía del exilio así como la biografía de un colectivo; por ello se desvía hacia las apreciaciones sobre la idiosincrasia del pueblo ruso, sobre su generosidad, espíritu compasivo y bondad hospitalaria, muy notable en las mujeres, según su apreciación; también destaca su fatalismo originado por el hábito al sufrimiento. Es importante mencionar la economía de medios y el tono sobrio de la narración como una característica de esta escritura, acorde con las mencionadas intenciones de la autora.

También vale la pena destacar las continuas referencias a las amigas con las que se reencuentra en su largo exilio, la amistad femenina aparece tematizada de ese modo, así como es mucho mayor el espacio dedicado a retratar a las mujeres, a contar sus acciones y padecimientos con lo que subraya el protagonismo femenino de estas historias.

La denuncia del machismo también tiene su espacio cuando cuenta la actitud del partido comunista de España que, 
luego del suicidio de José Díaz, su dirigente máximo en el exilio, se mostró reticente a que Dolores Ibárruri asumiera la dirección vacante. A pesar de todo su desencanto y su implacable denuncia del régimen comunista, Parga hace un reconocido homenaje a la Pasionaria, retratándola con admiración con lo que hace un homenaje a su figura.

El recuento de lo ocurrido en el exilio mexicano ocupa un breve espacio, tan sólo las páginas finales de estas memorias. La primera impresión que le produjo extrañeza a la familia Tagüeña Parga, al arribar a tierra mexicana, fue que todos hablaran español. Parece que una vez denunciada la farsa comunista, queda poco que decir de este país que acoge a la autora y a su familia para establecerse por siempre. Salvo las alusiones a la fanática inmigración española que los consideraba como traidores por ser disidentes del comunismo, poco más se dice aunque agradece la acogida al generoso país, la seguridad y la libertad que le permitió a los exiliados y a sus descendientes. No deja sin embargo de hacer una pequeña alusión al gran anhelo de todo expatriado: la esperanza de volver.

La obra se cierra con un epílogo en el que la autora se ubica plásticamente en el espacio geográfico mexicano, como afirmación de su afincamiento definitivo en esas tierras. Degustando la sonoridad de los topónimos indígenas, la autora no escribe, hace memoria de lo contado.

De seguidas expone de nuevo su proyecto testamentario, cerrando el círculo textual abierto en el prólogo justificativo y avanzando hacia los acontecimientos que se suceden en el momento histórico en que la autora reflexiona. Su preocupación por los conflictos sociales, por las injusticias que padecen "los desheredados de la tierra", así como su reconocimiento de las conquistas alcanzadas gracias a la revolución rusa, dejando aparte los excesos de la época estalinista, culminan el perfil de 
mujer revolucionaria, con profundas preocupaciones sociales, que la autora ha modelado a lo largo de su relato.

Esta es otra constante que detectamos en las memorialistas del exilio republicano que asumieron compromisos políticos en una hora de decisivas actividades y confrontaciones ideológicas en España: la necesidad de dejar constancia de la sincera sensibilidad social que las caracterizó desde niñas. De modo que la escena de lectura, la alusión a la voraz afición a los libros que comentan los autores literarios en sus textos autobiográficos, es suplantada por lo que llamaríamos "la escena de la toma de conciencia de clase" en las memorialistas que se han dedicado a la política, además de aficionarse a la escritura. Se trata entonces de una característica que podríamos denominar con la frase que subtitula el famoso testimonio de Rigoberta Menchú: así me nació la conciencia.

Antes del punto final Carmen Parga no deja de inscribir su proyecto memorialístico dentro de la postura plutarquea al reafirmar su creencia en la universalidad enriquecedora de toda experiencia humana. Para ello cuenta la última anécdota, la que hace referencia a la muerte de un amigo que había solicitado que a su muerte sus cenizas fuesen esparcidas en el Mediterráneo, pero que poco antes de morir cambió su deseo, solicitando que la esparcieran en el Golfo de México "porque todo mar es mar"; así como "toda la tierra es tierra, pero sobre todo, todos los hombres son hombres..." (p. 177).

Resumo: Este artigo realiza uma breve análise de três obras de testemunbos do exílio escritas por mulberes: Victoria Kent, destacada advogada socialista comprometida com o governo da República espanbola, Dolores Ibárruri, a mítica Pasionaria, e Carmen Parga, republicana exilada na Rússia e México. As três dão sua visão, a sua maneira e através da 
escrita, sobre o drama vivido oferecendo sua concepção particular do exilio. Antes de entrar nas obras aludidas, examina-se brevemente as duas concepções sobre a dramática experiência do exilado que Claudio Guillén reconbeceu na escrita dos clássicos: Ovidio e Plutarco.

\section{Bibliografia}

GUILLÉN, Claudio. El sol de los desterrados: Literatura y exilio: Barcelona: Quaderns Crema, 1995.

KENT,Victoria. Cuatro años en París (1940-1944). Málaga: Universidad de Málaga, 1997.

IBÁRRURI, Dolores. Memorias de Pasionaria. 1939-1977. Barcelona: Planeta, 1984.

NAHARRO-CALDERÓN, José (coord.). El exilio de las Españas de 1939 en las Américas: "Adónde se fue la canción".

Barcelona: Anthropos, 1991.

MANGINI, Shirley. Recuerdos de la resistencia. Barcelona: Península, 1997.

PARGA, Carmen. Antes que sea tarde. Madrid: Compañía literaria, 1996.

SAMBLACAT, Neus. "Las barricadas de la memoria: a propósito de algunos testimonios de guerra de mujeres exiliadas". Guaraguao, 5 Año 2, 1997. 